\title{
D-Methionine protects against cisplatin-induced neurotoxicity in cortical networks
}

\author{
Kamakshi V. Gopal ${ }^{\text {a,c,* }}$, Calvin Wu ${ }^{\text {a,b,c }}$, Bibesh Shrestha ${ }^{\text {a,c }}$, Kathleen C.M. Campbell ${ }^{\text {d }}$, \\ Ernest J. Moore ${ }^{\mathrm{a}, \mathrm{c}}$, Guenter W. Gross ${ }^{\mathrm{b}, \mathrm{c}}$ \\ ${ }^{a}$ University of North Texas, Department of Speech \& Hearing Sciences, United States \\ ${ }^{\mathrm{b}}$ University of North Texas, Department of Biological Sciences, United States \\ c University of North Texas, Center for Network Neuroscience, United States \\ d Southern Illinois University School of Medicine, Department of Surgery, United States
}

\section{A R T I C L E I N F O}

\section{Article history:}

Received 5 December 2011

Received in revised form 10 June 2012

Accepted 11 June 2012

Available online 23 June 2012

\section{Keywords:}

Cisplatin

D-Methionine

L-Methionine

Microelectrode array

Auditory cortex

In vitro network

\begin{abstract}
A B S T R A C T
Cisplatin is a platinum-based chemotherapeutic agent widely used for the treatment of various types of cancer. Patients undergoing cisplatin treatment often suffer from a condition known as "chemobrain", ototoxicity, peripheral neuropathy, weight loss, nausea, vomiting, nephrotoxicity, seizures, hearing loss and tinnitus. D-Methionine (D-Met), a sulfur-containing nucleophilic antioxidant, has been shown to prevent cisplatininduced side effects in animals without antitumor interference. In this study, we have used an in vitro model of cortical networks (CNs), enriched in auditory cortex cells; to quantify cisplatin neurotoxicity and the protective effects of D-Met. Dissociated neurons from auditory cortices of mouse embryos were grown on microelectrode arrays with 64 transparent indium-tin oxide electrodes, which enabled continuous optical and electrophysiological monitoring of network neurons. Cisplatin at $0.10-0.25 \mathrm{mM}$ induced up to a $200 \%$ increase in spontaneous spiking activity, while concentrations at or above $0.5 \mathrm{mM}$ caused irreversible loss of neuronal activity, accompanied by cell death. Pretreatment with D-Met, at a concentration of $1.0 \mathrm{mM}$, prevented the cisplatin-induced excitation at $0.10-0.25 \mathrm{mM}$, caused sustained excitation without occurrence of cell death at $0.5 \mathrm{mM}$, and delayed cell death at $0.75 \mathrm{mM}$ cisplatin. L-Methionine, the optical isomer, showed lower potency and less efficacy than D-Met, was less protective against $0.1 \mathrm{mM}$ cisplatin, and proved ineffective at a concentration of $0.5 \mathrm{mM}$ cisplatin. Pre-exposure time of D-Met was associated with the protective effects at 0.1 and $0.5 \mathrm{mM}$ cisplatin, with longer pre-exposure times exhibiting better protection. This study quantifies as a function of concentration and time that D-Met protects central nervous system tissue from acute cisplatin toxicity.
\end{abstract}

(C) 2012 Elsevier Inc. All rights reserved.

\section{Introduction}

Cisplatin (cis-diamminedichloroplatinum(II) - CDDP) is a platinumbased chemotherapeutic agent commonly used in treating various types of cancer (Kovarík et al., 1972; Stathopoulos, 2010). Cisplatin exerts its cytotoxic effect through the formation of DNA adducts that trigger cell death by apoptosis (Eastman, 1990; Jamieson and Lippard, 1999). However, its antitumor action is associated with adverse effects such as neurotoxicity, ototoxicity, weight loss, nausea, vomiting, and nephrotoxicity (Brock et al., 2012; Lynch and Kil, 2005; Rajeswaran et al., 2008; McWhinney et al., 2009). Neurotoxicity is often severe, as cisplatin crosses the blood-brain barrier and can accumulate through repeated dosages (Kaasa et al., 1988; Namikawa

\footnotetext{
* Corresponding author at: Dept. of Speech \& Hearing Sciences, University of North Texas, 1155 Union Circle \#311277, Denton, TX 76203-5010, United States. Tel.: + 1940 565 2481(Voice); fax: +1940 5654058.

E-mail address: gopal@unt.edu (K.V. Gopal).
}

et al., 2000), causing demyelination, axonal shrinkage, neurofibrillar accumulations, and vacuolar changes in the white matter (Olivi et al., 1993). Cisplatin commonly induces "chemobrain", a cognitive decline that occurs in a majority of patients (Whitney et al., 2008).

The central auditory nervous system (CANS), an intricate neural pathway that is primarily engaged in complex pattern analysis of acoustic signals, is highly vulnerable to neurotoxicity. Hearing loss induced by ototoxicity or neurotoxicity is characterized by irreversible hearing threshold deficits sometimes associated with tinnitus. As reviewed by Rybak (2005), hearing loss occurs in 30 to $100 \%$ of patients treated with cisplatin. Hearing loss may occur during treatment (Knight et al., 2005, 2007; Orgel et al., 2012) or after discontinuation of chemotherapy (Al-Khatib et al., 2010; Kolinsky et al., 2010). Furthermore, patients treated with cisplatin exhibit severe difficulty in word recognition (Einarsson et al., 2011), suggesting a central component in their hearing loss.

Studies of cisplatin-induced hearing loss have generally focused on damage to the peripheral auditory system, with morphological 
alterations in the organ of Corti of the cochlea, loss of and damage of cochlear hair cells, damage to the stria vascularis and degeneration of spiral ganglion neurons (Campbell et al., 1996, 1999; Meech et al., 1998; Hoistad et al., 1998). Cisplatin has been shown to enhance the formation of reactive oxygen species, and the free radicalinduced cell damage is thought to play an important role in cisplatin neurotoxicity (Dehne et al., 2001; Poirrier et al., 2010). Although cisplatin is known to be neurotoxic and is believed to exacerbate the impact of the peripheral cisplatin-induced ototoxicity, its effects on the central auditory system are not well characterized. Cisplatin has been shown to alter the central conduction time ( $\mathrm{I}-\mathrm{V}$ interval) of the auditory brainstem response and prolong cortical-evoked potentials from tibial nerve stimulation, suggesting adverse effects on the central nervous system (Hansen et al., 1989). Cisplatin induced tinnitus, a common complaint among sufferers, may also be central in origin (Rybak, 2005).

These adverse effects from cisplatin exposure have led to the search for preventative treatments (Campbell et al., 1996, 1999; Rybak et al., 2007). Sulfur containing compounds such as sodium thiosulfate (STS) and diethyl-dithiocarbamate (DDTC) were reported to provide good otoprotection against cisplatin (Otto et al., 1988), but had significant side effects and/or interference with antitumor activity (Jones et al., 1991; Church et al., 1995; Gandara et al., 1995; Muldoon et al., 2000). D-Methionine (D-Met), also a sulfur-containing nucleophilic antioxidant, has shown to provide effective nephroprotection against cisplatin without interfering with antitumor action (Jones and Basinger, 1989). Cisplatin-induced hearing loss, and subsequent outer hair cell loss and stria vascularis damage, is protected by D-Met (Campbell et al., 1996, 1999). In the cochlea, D-Met partially protected cisplatin-induced decreases in antioxidant enzymes such as superoxide dismutase (SOD), catalase, and glutathione a reductase (GR), and prevented increases in malondialdehyde levels, a measure of lipid peroxidation (Campbell et al., 2003). Several animal studies have shown that D-Met prevented oxidative-stress induced ototoxicity and nephrotoxicity from cisplatin treatment (Campbell et al., 1996; Reser et al., 1999). Hamstra et al. (2010) evaluated the safety of the MRX-1024 - the bioavailable suspension of D-Met - in cancer patients. They showed that MRX1024 decreased the rate and severity of oral mucositis, with no significant increase in toxicity. D-Met has been regarded as a potential otoprotective agent, and is in human clinical trials for prevention of noise induced hearing loss. Although D-Met crosses the blood brain barrier, its effects on cisplatin-induced changes in the central auditory networks remain unclear (Lauenstein et al., 1987).

The goal of this study was to evaluate the acute effects of cisplatin on central neuronal networks and assess the neuroprotective effects of D-Met. For that reason, we have used cultured networks (CNs) derived from auditory cortices of mouse embryos growing in vitro on microelectrode arrays (MEAs). Neuronal networks growing on MEAs, unlike brain slices, typically have superior adhesion, stability of cell-electrode coupling, and longevity (Gross, 2011; Potter and DeMarse, 2001). These networks exhibit spontaneous activity and are histiotypic (like the parent tissue) in their pharmacological responses (Gopal and Gross, 1996b; Gross and Pancrazio, 2007; Gopal and Gross, 2004; Xia and Gross, 2003). The in vitro environment allows precise, reproducible pharmacological manipulations with no homeostatic interference from other organs. Morphological changes of neurons in the networks can be correlated optically with electrophysiological changes, and network deterioration can be followed systematically, providing a platform for rapid, quantitative screening of new chemical and pharmaceutical compounds (Johnstone et al., 2010; Novellino et al., 2011; Wu et al., 2011). Mice have been extensively used as the mammalian animal model in physiological and pharmacological experiments. In vitro models allow a drastic reduction in the usage of animals and associated costs. They also show great promise for scaling to high throughput (Johnstone et al., 2010; Gross et al., 2006). The hypothesis of this study was that D-Met is protective against cisplatin-induced acute cytotoxicity as well as functional neurotoxicity.

\section{Methods}

\subsection{MEA fabrication and cell culture procedures}

In house fabrication and preparation of MEAs, as well as recording techniques have been described previously (Gross, 1979; Gross et al., 1985; Gopal and Gross, 1996a; Keefer et al., 2001a). Briefly, indiumtin oxide sputtered glass plates were photoetched, spin-insulated with methyltrimethoxysilane, cured, deinsulated at the electrode tips with laser shots and electrolytically gold-plated to reduce the interface impedance to $1 \mathrm{M} \Omega$ at $1.0 \mathrm{kHz}$. Butane flaming was used to generate $3.0 \mathrm{~mm}$ diameter hydrophilic adhesion islands for cell growth centered on the 64-electrode matrix.

The care and use of animals, as well as all procedures involving animals in this study were approved by and performed in accordance with the guidelines of the institutional animal care and use committee of the University of North Texas. Mouse embryos were extracted on day E17 from ICR mice after $\mathrm{CO}_{2}$ narcosis and cervical dislocation. Tissue from the auditory cortex regions was used to provide $\mathrm{CNs}$ enriched in auditory cortex cells. Auditory cortices (AC) located on the postereolateral surface and depths of the left temporal cortex were dissected (approximately $2 \times 2 \times 1 \mathrm{~mm}$ ) from the embryos. The standard culturing process published earlier was used in this study (Gopal and Gross, 1996a). The AC tissue was mechanically and enzymatically dissociated, triturated and mixed with Dulbecco's Modified Minimal Essential Medium (DMEM), supplemented with horse serum (4\%), fetal bovine serum (4\%), and $1.0 \mathrm{ml} / \mathrm{L} \mathrm{B} 27$ (optimized supplement containing vitamins, hormones and other growth factors). The cell suspension was seeded at a cellular concentration of $70 \mathrm{~K} / 100 \mu \mathrm{l}$ onto to the adhesion island (approximately $10 \mu \mathrm{m}^{2}$ area), previously treated with poly-D-lysine and laminin, and incubated at $37{ }^{\circ} \mathrm{C}$ in $10 \% \mathrm{CO}_{2}$ and $90 \%$ air atmosphere. The cultures were subjected to a $50 \%$ medium change twice weekly with fresh DMEM supplemented with $6.0 \%$ horse serum. The cultures used in this set of experiments on the average were 30 days in vitro.

\subsection{Drugs and solutions}

Drug concentrations were calculated to minimize major bulk volume changes to the $2.0 \mathrm{ml}$ constant volume experimental bath. D-Met (M9375), L-Met (M9625) and cisplatin (P4393) were obtained from Sigma-Aldrich (St. Louis, MO) in powder form. DMEM and B27 were obtained from GIBCO Products International, Inc. D-Met and L-Met were dissolved in autoclaved water to produce a $200 \mathrm{mM}$ stock solution; cisplatin was dissolved using $1.0 \mathrm{mg} / \mathrm{ml}$ in a saline solution $\left(0.9 \% \mathrm{NaCl}_{2}\right)$.

\subsection{Electrophysiological recordings}

MEAs were placed on sterile stainless steel recording chambers mounted on an inverted microscope stage at $37^{\circ} \mathrm{C}$ (Gross and Schwalm, 1994). The original medium was then replaced by fresh isoosmotic DMEM stock medium (without serum). The $\mathrm{pH}$ was maintained between 7.3 and 7.5 with a continuous $10 \mathrm{~mL} / \mathrm{min}$ stream of filtered $10 \% \mathrm{CO}_{2}$ in air mixed by a gas flow controller (AFC 2600PRO, Aalborg, Inc.), and confined by a cap with a heated indium-tin oxide (ITO) window to prevent condensation, allowing continuous microscopic observation (Rijal-Oli and Gross, 2008). Medium osmolarity was maintained at a constant $320 \mathrm{mOsm}$ by infusion of sterile water with a syringe pump set at approximately50 $\mu \mathrm{l} / \mathrm{h}$ to compensate for evaporation. The neuronal activity was recorded with a two-stage, 64channel amplifier system (Plexon, Dallas, TX), and digitized simultaneously at $40 \mathrm{kHz}$ using 64 digital signal processors (DSP). Total system gain was set to 10,000 . Spike identification and separation of multiple 
spikes recorded by a single electrode were accomplished with a real time template-matching algorithm (Plexon, Dallas, TX) to provide single-unit spike rate data. Each DSP could discriminate up to four different action potential waveforms or "active" units recorded by a single electrode. Multiple unit data were expressed as average network spike production per minute, and monitored in real time. Off-line analysis was performed using custom programs that allowed for burst pattern analysis based on spike integration with a time constant of $100 \mathrm{~ms}$ (Morefield et al., 2000).

Network neurons were monitored using electrophysiological and morphological recordings. All pharmacological experiments were conducted in serum-free medium as serum albumin is known to bind numerous chemical compounds (Parviz and Gross, 2006). Criteria for the acceptance of networks after a change to serum-free medium were: (a) a minimum of 30 neurons recorded and discriminated based on waveshapes, (b) signal to noise ratios of 2:1 or greater, and (c) a mean spontaneous network activity exceeding 50 spikes per minute. In addition, minute-to-minute average activity fluctuation was required to be at or below $15 \%$.

The neurotoxicity of cisplatin was quantified, and the potency and efficacy profiles of D-Met were established on par with its enantiomer, the essential amino acid L-Met. Protection was evaluated through varying concentration/time pretreatment with D-Met prior to the application of cisplatin. The goal of D-Met pretreatment was to effect a minimal change (or no change) in $\mathrm{CNs}$ from baseline reference activity in the presence of cisplatin. The glass carrier plate of the MEA and the transparent indium-tin oxide (ITO) electrode conductors allowed maximum optical access during recording, and the multisite readout from a total of 64 electrodes provided continuous action potential trains from many individual neurons discriminated on the basis of waveshapes. Although a 64 electrode MEA records only 5\% to $10 \%$ of the total number of neurons in the network, the resulting information is sufficient for the generation of reliable population responses that, when normalized and summed or averaged, yield highly reproducible electrophysiological and pharmacological data (Gross, 2011).

\subsection{Controls}

Spontaneously active networks have different baseline (reference) activity. Yet they display highly reproducible pharmacological responses. The simplest approach to tackle the issue of different baselines is to use the initial stabilized activity (i.e., activity recorded prior to application of any compound) of each culture as its own internal control (reference). Compound-induced activity is therewith normalized and expressed as percent decrease from the internal reference. This approach provides reproducible concentration-response curves obtained from different networks and even allows calculation of dissociation constants (Rijal-Oli and Gross, 2008). To demonstrate long term stability in our preparation, we have added data to Figs. $1 \mathrm{~A}$ and $3 \mathrm{~A}$ depicting monitored activity for $7 \mathrm{~h}$ in CNs that were exclusively treated with only the vehicles, i.e., saline (used to dissolve cisplatin) or water (used to dissolve D- and L-Methionine). If aliquot volumes do not exceed $5 \%$ of the total volume, no osmolarity effects are noticed and network activities remain in a steady plateau state (Gross and Pancrazio, 2007).

To identify the pharmacological up- or down-regulation of neuronal activity, all electrophysiological data were expressed as percent change from reference activity (internal control). Activity variables used were mean spike rate and mean burst rate averaged across all discriminated units within the culture, and stability of waveshapes. Bursts are spike clusters and were identified operationally by digital RC integration with rise time constants of approximately $100 \mathrm{~ms}$ (Gopal and Gross, 2004; Parviz and Gross, 2006).

\subsection{Data analyses}

The reference activity of neurons remained stable in a serum-free DMEM stock solution in an environment of $\mathrm{pH}=7.4,37 \pm 1{ }^{\circ} \mathrm{C}$, with osmolarity maintained in the range of 300-320 mOsm (Gross et al., 1995; Keefer et al., 2001a, 2001b). The reference activity was recorded for a minimum of $30 \mathrm{~min}$ after a medium change from serum containing to serum-free medium. Response variability (after normalization) between different networks was expressed as \pm the standard error of mean (SEM). An activity change of $0 \%$ indicated that the network remained at reference activity after compound addition. Network responses were characterized as excitatory if there was an increase in spike activity compared to reference level, and inhibitory if there was a decrease in spike activity. A lack of acute recovery or return to reference levels was considered an important indicator of latent, possibly toxic compound effects. It was always measured after two complete medium changes with an observation interval of $30 \mathrm{~min}$. Therefore, a $100 \%$ recovery indicated a return to baseline or reference activity within $30 \mathrm{~min}$. Slower recoveries were not addressed and will be the subject of future studies.

Statistical analyses and concentration-response curve fitting used Origin software (Origin Lab, Northampton, MA). Differences in spike rates between $\mathrm{CNs}$ treated with cisplatin (with or without D-Met) and control (saline) CNs, were statistically analyzed using a one-way analysis of variance (ANOVA) followed by Tukey's post-hoc test. Students' T-tests were used for comparing spike rate data from CNs exposed to cisplatin with and without D-Met pretreatment.
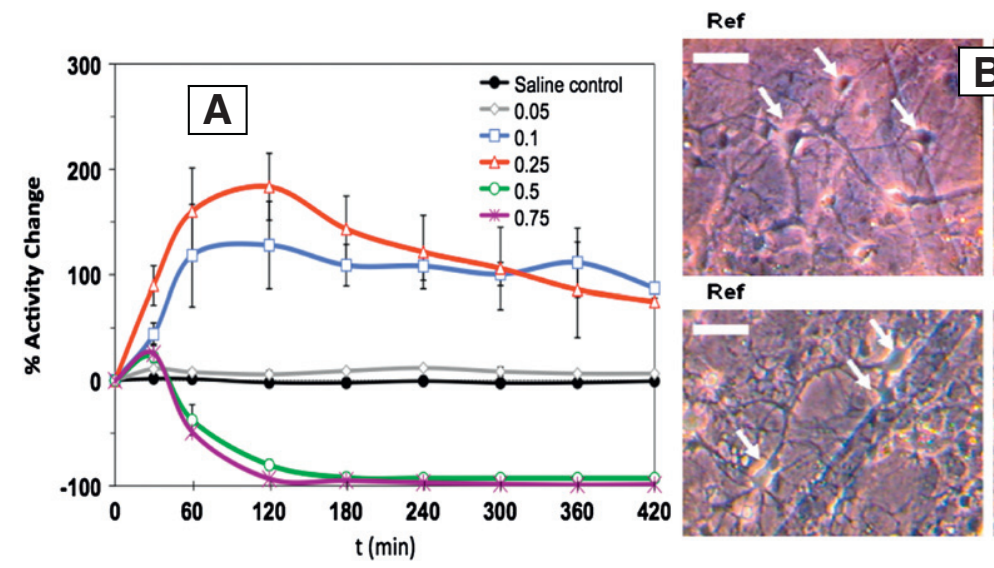

$0.25 \mathrm{mM}$ Cisplatin

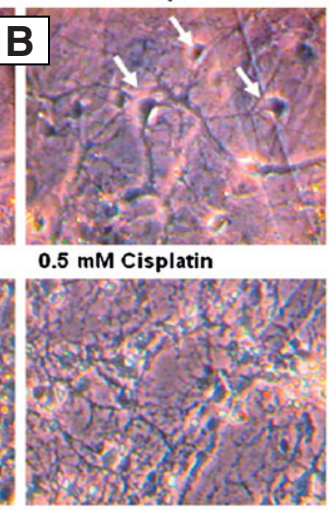



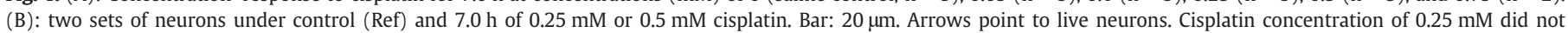
show obvious morphological changes of neurons (arrows), but $0.5 \mathrm{mM}$ cisplatin induced cell death (no arrows). 


\section{Results}

\subsection{Toxicity of cisplatin}

Spontaneously active neurons from CNs were recorded for an average experimental time period of $7.0 \mathrm{~h}$. Cisplatin induced excitation was characterized by an increase in mean spike activity for concentrations ranging from 0.05 to $0.25 \mathrm{mM}$ (Fig. 1A). Increasing concentrations within this range exhibited steeper slopes of excitation. Network responses were plotted as percent activity change from a 30-min reference activity period (not shown on data graphs).

Cisplatin at $0.05 \mathrm{mM}$ showed a minimal increase in spike activity ( 5.8 to $11.9 \%, \mathrm{n}=3$ ); while cisplatin at $0.10 \mathrm{mM}$ had an average maximum increase of $118.1 \pm 41.4 \%$ after the first hour of exposure, and $111.5 \pm 32.5 \%$ after $7.0 \mathrm{~h}(\mathrm{n}=3)$ of exposure. Cisplatin at $0.25 \mathrm{mM}$ had the highest increase of $183.4 \pm 31.5 \%(n=3)$, with a rapid rise, maximizing at $2.0 \mathrm{~h}$, before gradually leveling off to $85.8 \pm 45.2 \%$ $(\mathrm{n}=3)$. All excitatory phases were sustained for more than $7.0 \mathrm{~h}$. Experiments that were monitored for $24 \mathrm{~h}$ still showed excitation, leveling off to $80.3 \pm 5.5 \%$ (data not shown). At concentrations of $0.5 \mathrm{mM}$ and $0.75 \mathrm{mM}$, respectively, a brief period of minimal excitation was observed, followed by a marked decrease in activity. With cisplatin exposure at $0.5 \mathrm{mM}(\mathrm{n}=5), 50 \%$ and $90 \%$ activity losses were seen at 60 and $180 \mathrm{~min}$, respectively. Cisplatin at the $0.75 \mathrm{mM}$ concentration showed a $50 \%$ reduction within $60 \mathrm{~min}$, with cessation of activity after $180 \mathrm{~min}$.

In order to identify morphological changes in neurons, neuronal processes and glia cells were visually monitored throughout the experiments, and photographs were taken periodically. Fig. 1B shows two sets of neurons in reference medium (top, left; bottom, left) and after $7.0 \mathrm{~h}$ of exposure to cisplatin at $0.25 \mathrm{mM}$ (top panel, right) or $0.5 \mathrm{mM}$ (bottom panel, right). There were no overt changes in neuronal morphology (phase bright cells, arrows, ref panels), identified after $7.0 \mathrm{~h}$ of exposure to cisplatin at $0.25 \mathrm{mM}$ (top panel, right). Therefore, live neurons can be identified for reference (top and bottom panel, left) and cisplatin-treated conditions (top panel, right). However, due to extensive cell death after $7.0 \mathrm{~h}$ of exposure to $0.5 \mathrm{mM}$ cisplatin, neurons with normal morphology could no longer be identified (bottom panel, right).

\subsection{Concentration response characteristics of D-Met and L-Met exposure}

Prior to identifying the potential protective effects of D-Met or L-Met, the pharmacological profiles related to potency and efficacy were characterized. Both isomers of the drugs showed a decrease of spike activity with an increase in concentration (Fig. 2).

D-Met exhibited maximal efficacy (complete inhibition of neuronal spike activity) and potency expressed by the inhibitory concentration $\left(\mathrm{IC}_{50}\right)$ of $1.03 \pm 0.21 \mathrm{mM}(\mathrm{n}=4)$. In comparison to D-Met, the endogenous isomer L-Met, was found to be less effective with a maximum inhibition of $33.1 \pm 0.2 \%$, and an $\mathrm{EC}_{50}$ of $0.64 \pm 0.05 \mathrm{mM}$ $(\mathrm{n}=3)$. Based on these results, the $\mathrm{IC}_{50}$ value for D-Met $(1.0 \mathrm{mM})$ was chosen to assess its protective effects in subsequent experiments along with cisplatin exposure. No morphological changes in the neurons were observed with $1.0 \mathrm{mM}$ D-Met application (Fig. 3B, middle panel) or $1.0 \mathrm{mM}$ L-Met application (data not shown).

\subsection{Protection with $\mathrm{D}-\mathrm{Met}$}

Pretreatment with $1.0 \mathrm{mM}$ D-Met for $1.0 \mathrm{~h}$ prior to cisplatin exposure had varying effects, depending on the cisplatin concentration (Fig. 3A). In the presence of D-Met, CNs exposed to 0.10 and $0.25 \mathrm{mM}$ cisplatin exhibited substantial attenuation of excitation. The data show a time-dependent excitation profile for cisplatin at $0.5 \mathrm{mM}$, with maximal excitation of $156 \%$ compared to reference at approximately $120 \mathrm{~min}$. The excitation gradually leveled off to $44 \%$ at $7.0 \mathrm{~h}$. With an

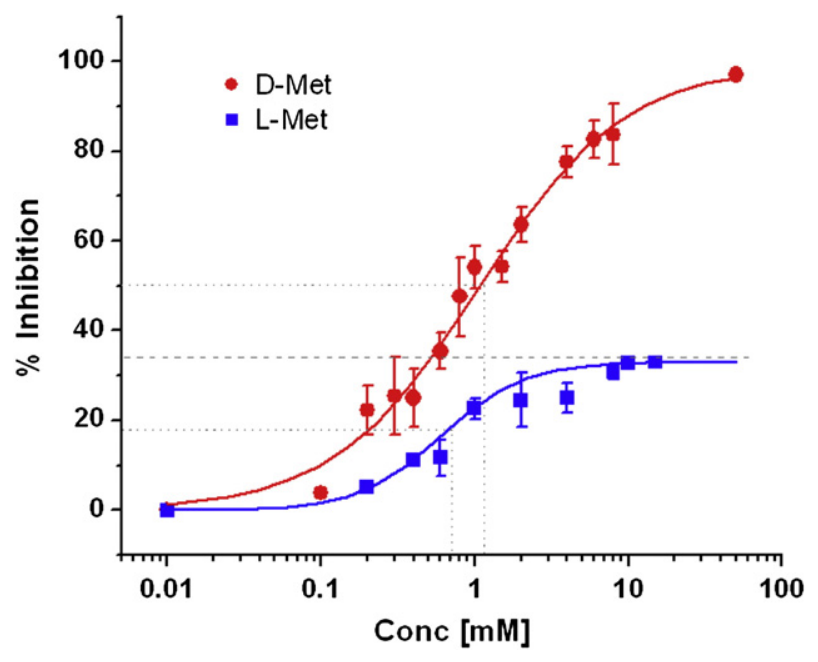

Fig. 2. Concentration-response curve of D-Met $(n=4)$ and $L-M e t ~(n=3)$. The $I_{50} \pm S E M$ values were $1.03 \pm 0.21 \mathrm{mM}$ (Hill slope: 0.94 ), and $0.64 \pm 0.05 \mathrm{mM}$ (Hill slope: 1.54 ), respectively. Note: L-Met has maximal efficacy of only $33 \%$ at a maximal concentration of $10 \mathrm{mM}$.

application $0.75 \mathrm{mM}$ cisplatin, there was an initial excitatory phase, followed by a shutdown of the network. In comparison to Fig. 1B, which shows extensive cell death when CNs are exposed to $0.5 \mathrm{mM}$ without D-Met pretreatment, Fig. 3B (upper panel) depicts the protection provided by D-Met at $0.5 \mathrm{mM}$ cisplatin exposure. However, cell death and shutdown of the network were unavoidable when the cisplatin concentration was increased to $0.75 \mathrm{mM}$ (Fig. 3A, and lower panel of Fig. 3B).

Fig. 3C depicts the results of a one-way ANOVA followed by Tukey's post-hoc test. Percent change of spike rate in CNs treated with cisplatin for $180 \mathrm{~min}$ (with and without D-Met) was compared to saline control $\mathrm{CNs}$. The independent variable was the concentration of cisplatin. Comparisons were made between cisplatin concentrations of 0 (control), $0.1 \mathrm{mM}, 0.25 \mathrm{mM}, 0.5 \mathrm{mM}$ and $0.75 \mathrm{mM}$. Results showed significant differences $(p<0.05)$ between control and each of the cisplatin concentrations, indicating substantial changes in network activity in the presence of cisplatin.

In order to identify if pretreatment with D-Met was protective, comparisons were made between CNs exposed to cisplatin with and without D-Met pretreatment using Students' T-Tests (also shown in Fig. 3C). Results indicated significant differences $(p<0.05)$ between $\mathrm{CNs}$ exposed to cisplatin alone and CNs exposed to cisplatin in the presence of D-Met. Since the goal of D-Met pretreatment was to provide protection against cisplatin toxicity, less change in activity (i.e., activity that remains close to the zero baseline in Fig. 3C) was considered optimum. Further, if the change in activity was negative as opposed to positive, it was considered more adverse because of the possibility of further deterioration of activity leading to network shutdown.

To identify if voltage-gated sodium or potassium channels were involved with cisplatin and/or D-Met exposure, we examined AP waveforms. Fig. 4A depicts representative waveforms from a discriminated unit with no cisplatin (reference), and $0.5 \mathrm{mM}$ cisplatin exposure for $30 \mathrm{~min}$ and $480 \mathrm{~min}$. Although the activity was close to zero at 180 min (Fig. 1A), some units in the networks continued to fire at low frequencies, and one of those units was used in the analysis. Fig. $4 \mathrm{~B}$ shows a similar sample of waveforms from a network pretreated with D-Met. For quantification, AP amplitudes and AP widths were measured. P1-P2 and P2-P3 refer to amplitude measures (in $\mu \mathrm{V}$ ), and $\mathrm{W}$ (width) indicates the time interval (in $\mu$ ) at the $0 \mu \mathrm{V}$ baseline between P1 and P3. Mean \pm SEM amplitude and width measurements from 9 units (3 neurons from 3 different CNs) were analyzed using one-way ANOVA. The independent variable was the exposure time under cisplatin. Comparisons were made between waveshapes at the reference 

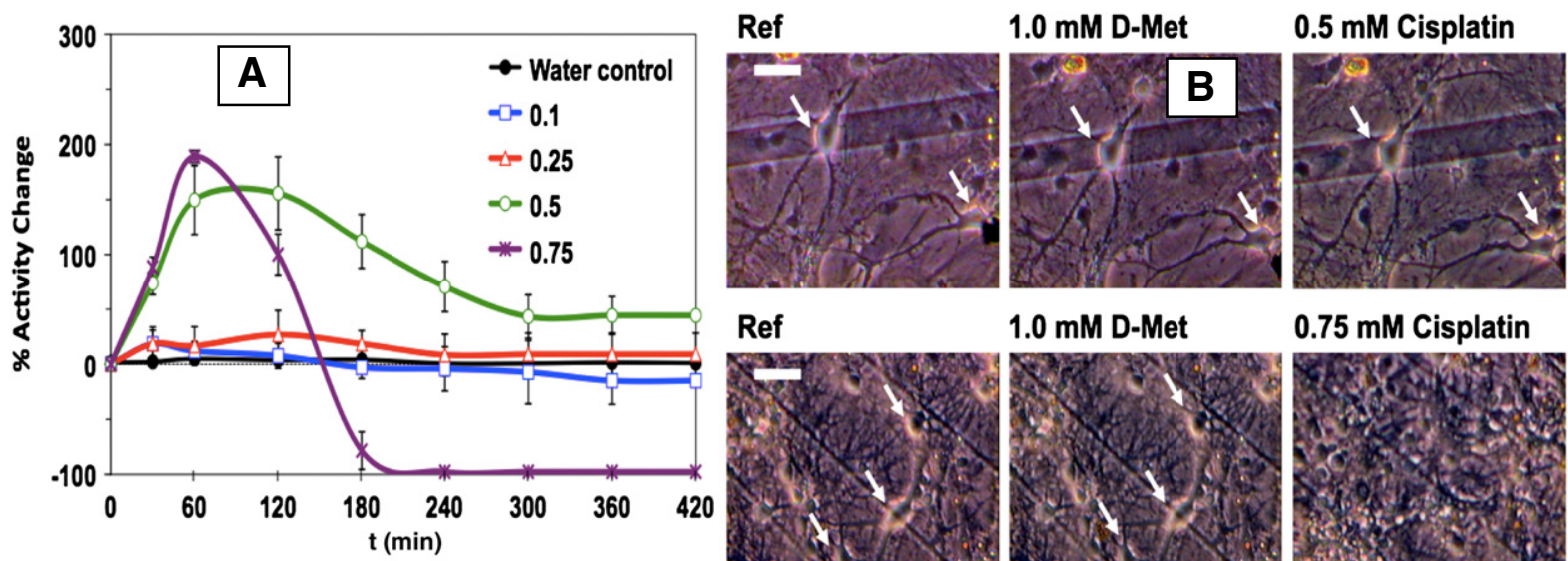

Ref



$1.0 \mathrm{mM}$ D-Met

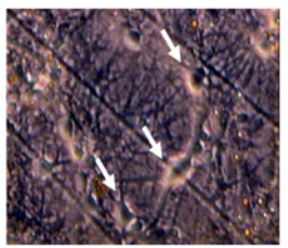

$0.75 \mathrm{mM}$ Cisplatin



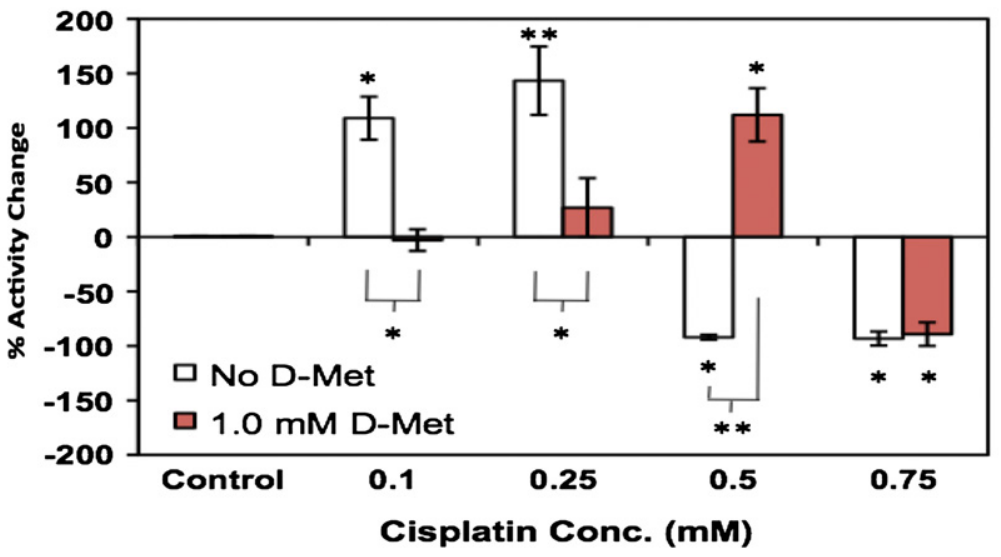



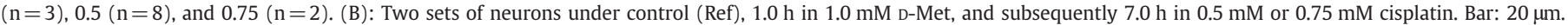

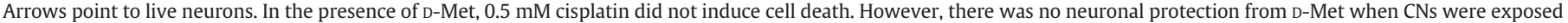

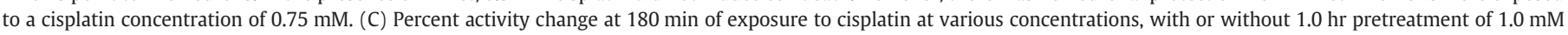

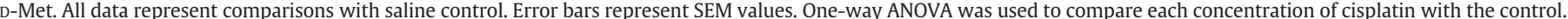

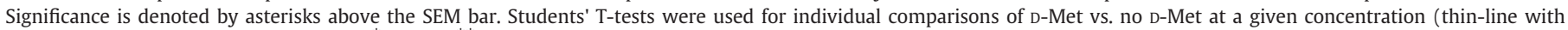
significance asterisks below the symbol). ${ }^{*} \mathrm{p}<0.05,{ }^{* *} \mathrm{p}<0.001$.

condition and at 30 or 480 min of exposure to cisplatin. Results indicated no statistically significant differences ( $\mathrm{p}>0.75$ for P1-P3, P2-P3 and W). These observations suggest no voltage-gated sodium or potassium channel involvement with cisplatin or D-Met exposure.

\subsection{Recovery from cisplatin exposure}

To ascertain latent effects, we assessed recovery of network activity in terms of the degree of return to its reference level following two washes. The rationale was that irreversible loss of activity, even after two complete medium changes, indicates permanent damage to the networks, generally associated with cytotoxicity. However, a persistent increase in spike and burst activity following washes is indicative of functional changes in the network, for which the exact mechanisms are still unclear.

Fig. 5A depicts lack of recovery in a $\mathrm{CN}$ exposed to cisplatin alone. Similar to the data shown earlier (Fig. 1A), the culture in Fig. 5A showed an increase in activity in the presence of $0.25 \mathrm{mM}$ cisplatin,
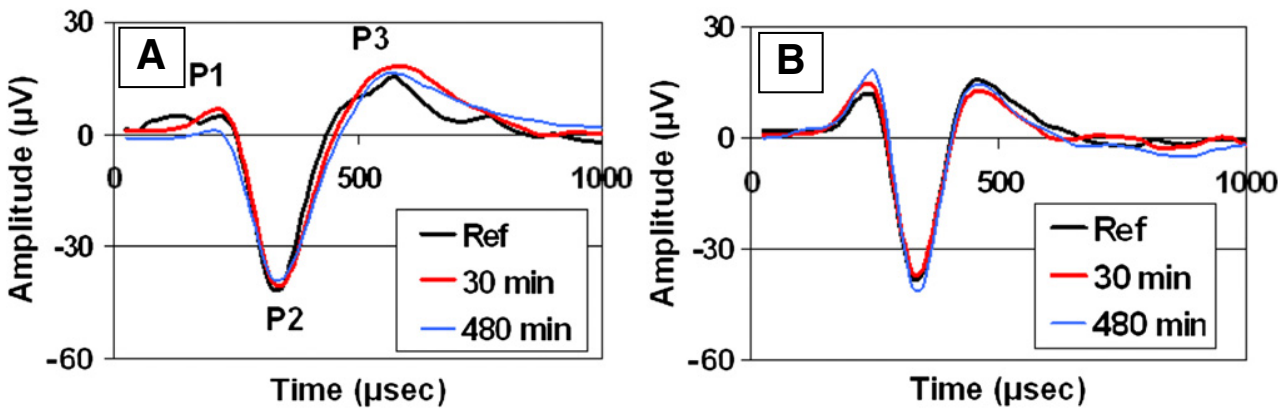

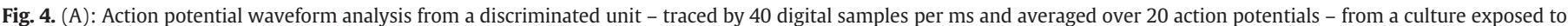



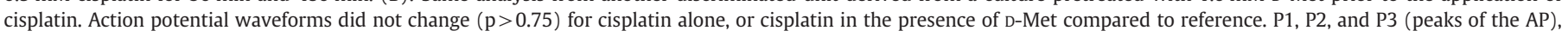
and $\mathrm{W}$ (width of AP) were used for statistical analyses. 

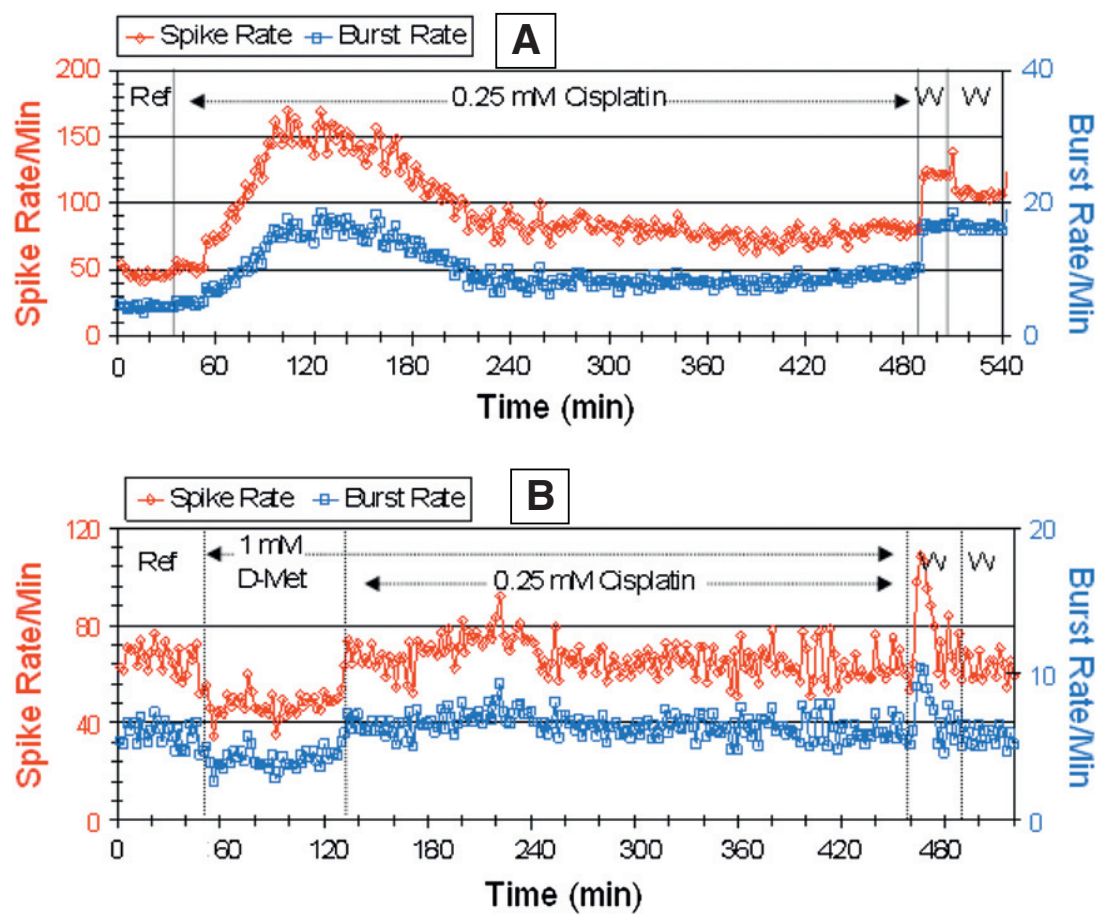

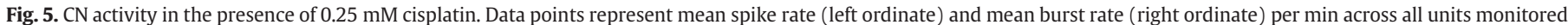

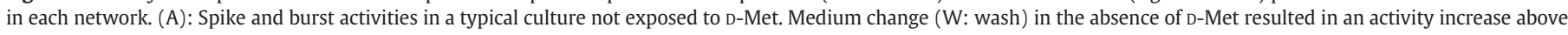

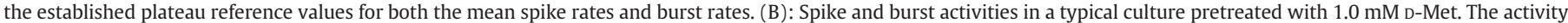
following the washes returns to the reference level in CNs exposed to D-Met prior to cisplatin application.

with a rapid rise around 120 min and gradually leveling off. The spike and burst rates were found to be above the reference level for more than $7.0 \mathrm{~h}$, and remained at that level despite two complete medium changes. This observation suggests functional neurotoxicity possibly from cell stress and partial damage to the networks. Fig. 5B shows the results from a CN pretreated with D-Met. When the culture was pretreated with $1.0 \mathrm{mM}$ D-Met, the cisplatin-induced spike and burst activities were not only comparable to the reference activity, but remained so following two washes.

Fig. 6 shows averaged data from multiple CNs exposed to various concentrations of cisplatin alone, and in the presence of D-Met $(n=3$ for each category, 24 experiments total). Cisplatin concentrations of $0.1 \mathrm{mM}$ and $0.25 \mathrm{mM}$ exhibited spike and burst activities at much higher levels than reference $(177.3 \pm 25.7 \%$ and $224.7 \pm 28.9 \%$ respectively).

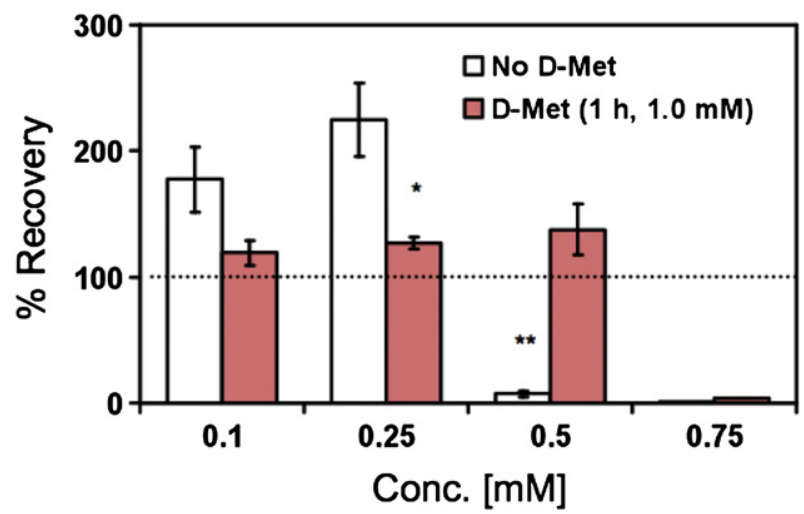

Fig. 6. Percent recovery of spike activity in $\mathrm{CNs}$ from wash after exposure to various concentrations of cisplatin for $7.0 \mathrm{~h}$, with or without $1.0 \mathrm{~h}$ of pretreatment with $1.0 \mathrm{mM}$ D-Met. The dotted line at $100 \%$ indicates recovery to the reference condition at 30 min after wash. ${ }^{*} \mathrm{p}<0.05,{ }^{* *} \mathrm{p}<0.001$.
This increase persisted after two medium changes. Recovery from $0.5 \mathrm{mM}$ cisplatin was minimal. However, the activity in CNs pretreated with $1.0 \mathrm{mM}$ D-Met for $1.0 \mathrm{hr}$ showed recoveries that were close to the reference. In D-Met pretreated CNs exposed to $0.1 \mathrm{mM}$ cisplatin, the recovery was close to the reference $(119.0 \pm 10.1 \%)$, but not significantly different from the recovery that was seen without D-Met pretreatment (Students's $T$-test, $\mathrm{p}=0.09$ ). At $0.25 \mathrm{mM}$ cisplatin, the recovery under D-Met was $127.0 \pm 5.0 \%$, which was significantly better than the recovery seen without $\mathrm{D}-M e t$ treatment $(\mathrm{p}=0.025)$. Major protection was observed in CNs pretreated with D-Met and exposed to $0.5 \mathrm{mM}$ cisplatin $(137.7 \pm 20.4 \%)$, a stark contrast to irreversible activity loss seen in CNs without $\mathrm{D}-$ Met pretreatment $(\mathrm{p}<0.0003)$. There was no recovery with exposure to cisplatin at $0.75 \mathrm{mM}$, even if the cultures were pretreated with D-Met. These observations indicate that D-Met not only limits cisplatin-induced activity changes, but also reverses the cisplatininduced activity changes after washes, up to a cisplatin concentration of $0.5 \mathrm{mM}$. This demonstrates that D-Met protects against cisplatininduced acute functional neurotoxicity as well as cytotoxicity at $0.5 \mathrm{mM}$.

\subsection{Comparison of protection with D-Met vs. L-Met}

To compare the protective effects of L-Met vs. D-Met, CNs were pretreated with $1.0 \mathrm{mM}$ of either compound for $1.0 \mathrm{~h}$ before application of cisplatin at concentrations of 0.1 or $0.5 \mathrm{mM}$ (Fig. 7A). No change from reference ( $0 \%$ activity change) with cisplatin exposure was the goal of D/L-Met pretreatment. For cisplatin exposure at $0.1 \mathrm{mM}$, L-Met was slightly less protective than D-Met. Unlike D-Met pretreated CNs, the spike activity in the CNs treated with L-Met did not remain close to reference. Instead, there was an increase in activity at $120 \mathrm{~min}$ $(31.7 \pm 4.5 \%)$ with L-Met, which gradually leveled off $(13.4 \pm 2.8 \%$, $\mathrm{n}=2$ ) after $7.0 \mathrm{~h}$. Exposure to $0.05 \mathrm{mM}$ cisplatin revealed a clear distinction between the effects of the two compounds. L-Met pretreatment initially showed a similar rising phase as D-Met, but was 

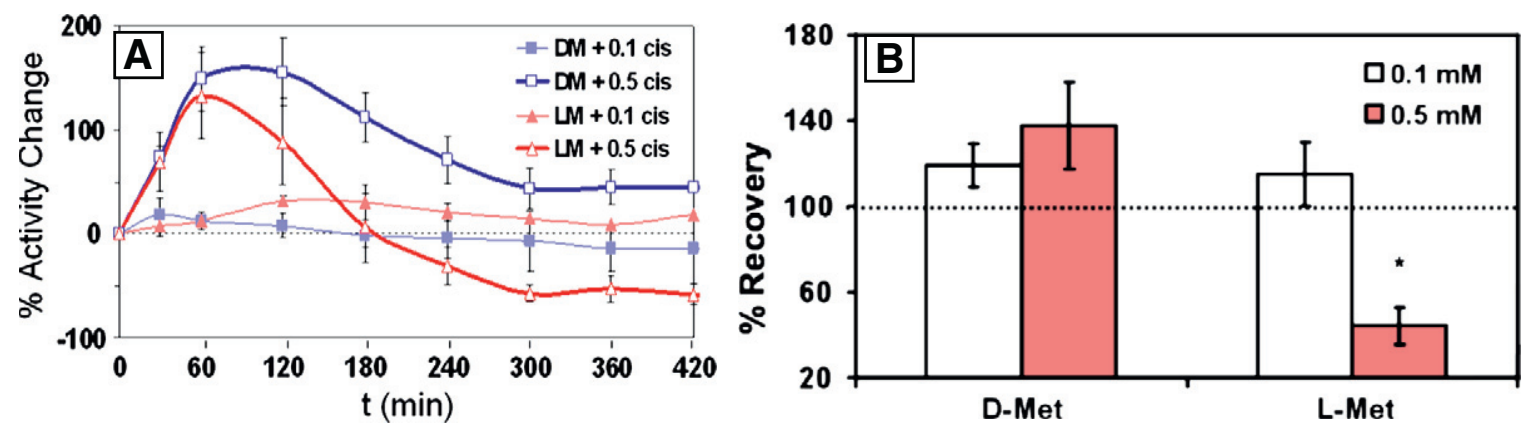

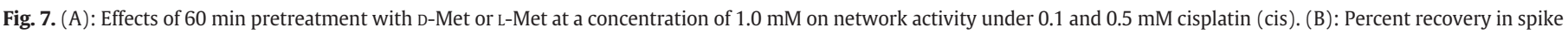

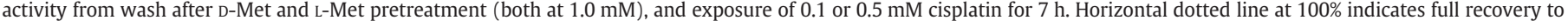
reference level. ${ }^{*} \mathrm{p}<0.05$.

followed by a more rapid decline of activity to less than $50 \%(n=5)$ by the end of $7.0 \mathrm{~h}$. In addition, the recovery data (Fig. 7B) showed a significant lack of recovery to reference in CNs exposed to L-Met under $0.5 \mathrm{mM}$ cisplatin (Students' $T$-test, $\mathrm{p}=0.018$ ). This indicates a less effective protection by L-Met.

\subsection{Effect of pretreatment time of D-Met protection}

To assess the effect of pretreatment time on protection using D-Met, different time periods of $0,30,60$ and 120 min were used prior to the addition of cisplatin for a $7.0 \mathrm{~h}$ exposure period (Fig. 8).

At $0.1 \mathrm{mM}$ cisplatin, a pretreatment time of $0 \mathrm{~min}$ (simultaneous application of D-Met and cisplatin) and a pretreatment time of $30 \mathrm{~min}$ induced excitatory activity to a greater degree than in cultures pretreated for $60 \mathrm{~min}$ or $120 \mathrm{~min}$. For the cisplatin exposure level of $0.5 \mathrm{mM}$, a 30 min pretreatment of D-Met did not prevent loss of activity $(-60.4 \pm 0.2 \%$ at $420 \mathrm{~min}, \mathrm{n}=5)$. A $60 \mathrm{~min}$ pretreatment prevented cell death, but caused excitation. A 120 min pretreatment resulted in significantly less excitation in the first hour of cisplatin exposure, and the activity gradually returned to reference activity after $3.0 \mathrm{~h}(10.1 \pm$ $7.2 \%, \mathrm{n}=2$ ). Simultaneous application of $1.0 \mathrm{mM}$ D-Met and $0.5 \mathrm{mM}$ cisplatin failed to provide protection $(n=2)$. Data on the recovery of network activity to reference level following two washes also showed a similar pattern (see Fig. 9). Without D-Met, recovery from $0.5 \mathrm{mM}$ cisplatin is significantly reduced, compared to recovery in the presence of $\mathrm{D}$-Met (Students' $T$-test, $\mathrm{p}=0.0002$ ). With simultaneous, and a 30 min pre-application, there was partial recovery, but again significantly greater than if $\mathrm{D}-$ Met was not added $(\mathrm{p}=0.048$, and $\mathrm{p}=0.013$, respectively). With pretreatment times of 60 and $120 \mathrm{~min}$, there was complete recovery with both concentrations tested $(0.1 \mathrm{mM}$ and $0.5 \mathrm{mM}$ )

\section{Discussion}

This study quantified acute electrophysiological and cellular toxic effects of cisplatin on in vitro cortical neuronal networks grown on MEAs, and assessed the protective effects of D-Met against cisplatininduced neurotoxicity. It is important to recall that in our study, all electrophysiological responses were first normalized by expressing them as percent activity change from the reference (baseline) state established for each network in the native, initial stages of recording. Thereafter, responses from different networks were comparable, allowing quantification of a variety of drug applications and activity variables. Acute responses normally occur at higher concentrations than chronic effects, but provide relatively rapid quantitative information. The average duration of such experiments in this study was $7.0 \mathrm{~h}$. Acute effects of cisplatin and protection by D-Met, despite occurring at the high end or outside the clinical range, must be established before assessing chronic effects. The latter studies are more laborious and time-consuming and can only be justified if reliable acute responses are demonstrated. In this study, we found that even at high concentrations of cisplatin, D-Met was protective. These results strengthen our rationale for future chronic studies of cisplatin at clinically relevant concentrations, using this research platform.

The typical cisplatin clinical dosage regimens vary from 50 to $100 \mathrm{mg} / \mathrm{m}^{2}$ (approximately 14 to $28 \mu \mathrm{M}$ ), administered intravenously every three to four weeks, usually for about 6 cycles. At times, a high dose of up to $120 \mathrm{mg} / \mathrm{m}^{2}$ is used in combination with other
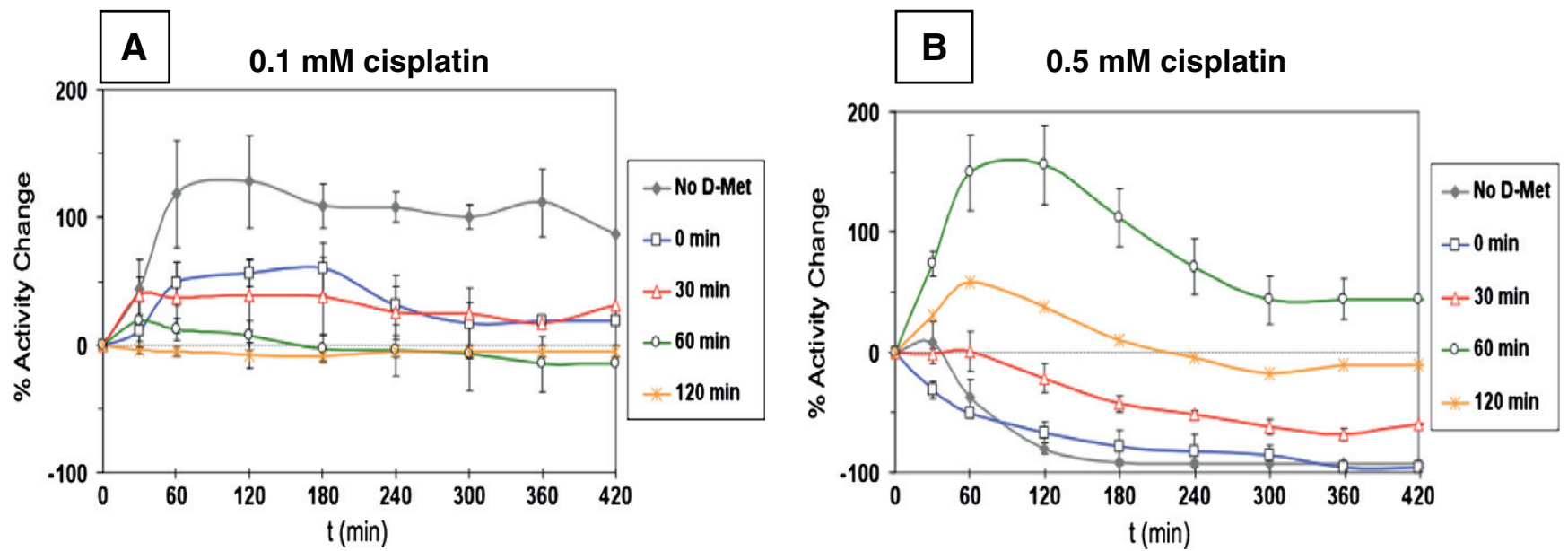

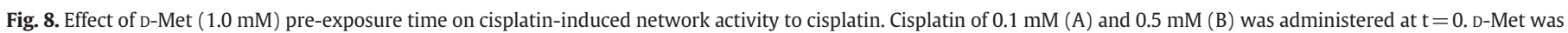
administered either simultaneously ("0 $\mathrm{min}$ "), $30 \mathrm{~min}, 60 \mathrm{~min}$ or $120 \mathrm{~min}$ prior to the addition of cisplatin. 


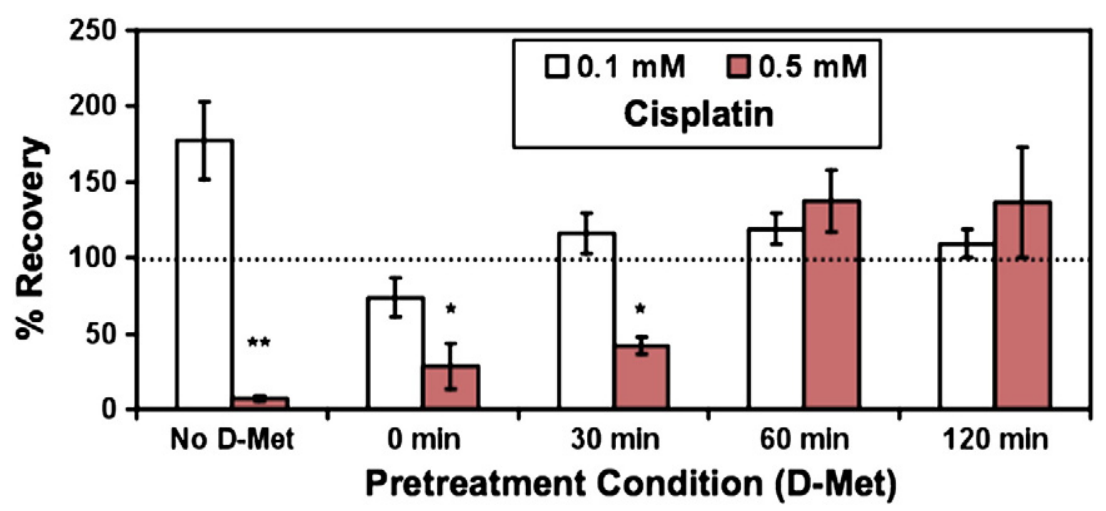

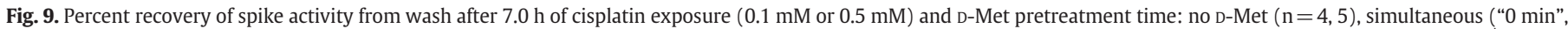

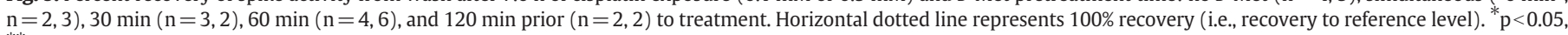
${ }^{* *} \mathrm{p}<0.001$.

antineoplastic agents for multiple times. With extrapolation from the maximum clinical dosage, the cisplatin concentrations used in this study include the upper limit of clinically relevant doses, as well as doses outside a physiological range. Our results indicate that cisplatin concentrations ranging from 0.1 to $0.25 \mathrm{mM}$ increased the mean spike activity in a concentration-dependent manner. This excitation lasted throughout the $7.0 \mathrm{~h}$ of recording, but was not associated with any overt morphological neuronal and glial damage.

It is speculated that a cisplatin-induced increase in spike activity may be related to the perception of tinnitus. Although tinnitus cannot be measured in an in vitro system, the tinnitus-like activity has been explored earlier using this same model. Gopal and Gross (2004), examined the acute effects of quinine (a tinnitus-inducing drug) on cultured auditory networks growing on MEAs. Quinine concentrations of 1.0-20.0 $\mu \mathrm{M}$ showed a significant increase in spike rate and burst rate compared to the baseline reference level. At higher concentrations of $30.0-40.0 \mu \mathrm{M}$, the spike rate decreased, but the burst rate continued to remain above the reference level. Quinine concentrations of greater than $5.0 \mu \mathrm{M}$ regularized burst patterns and increased the coordination of burst across the units. Thus the increase in burst pattern regularity coupled with the excitatory responses in auditory networks showed susceptibility of central auditory tissue to quinine, and was believed to be related to the underlying mechanism of tinnitus production. Wu et al. (2011) exposed spontaneously active auditory cortical networks growing on MEAs to pentylenetetrazol (PTZ), a proconvulsant and an antagonist of $\mathrm{GABA}_{\mathrm{A}}$ receptor, which is implicated in tinnitus. PTZ increased the spike and burst activities in the networks. However, when experimental tinnitus drugs pregabalin, linopirdine, L-Carnitine, or gabapentin were added to the PTZ exposed networks, significant reduction of the induced activity increase was observed. The potency of the experimental tinnitus drugs was linopirdine $>$ L-carnitine $>$ pregabalin $>$ gabapentin. It was concluded that auditory cortical network growing on MEAs was a feasible model for semi-high throughput drug screening applications for tinnitus treatment.

In this study, at higher concentrations of cisplatin (0.5 and $0.75 \mathrm{mM}$ ), there was initial excitation followed by a marked irreversible decrease in activity, associated with massive cell death. These electrophysiological and morphological observations from cortical tissue are in agreement with cell viability data published by Jiang et al. (2008), in which dorsal root ganglia were exposed to cisplatin for $24 \mathrm{~h}$ in culture. They observed that cisplatin dosage of $25 \mu \mathrm{M}$ had no significant effect on cell viability, however, at $400 \mu \mathrm{M}$, only about $4.0 \%$ of the cells survived.

Prior to assessing the effectiveness of D-Met pretreatment against cisplatin-induced electrophysiological and morphological changes in CNs, we evaluated the independent effects of D-Met on CNs. Application of D-Met alone (in the absence of cisplatin exposure) at concentrations of 0.1 to $10 \mathrm{mM}$ induced inhibition of activity CNs. However, no overt morphological changes in glia, neuronal somata, or neuronal processes were observed. The electrophysiological data indicated that the $\mathrm{IC}_{50}$ value for D-Met was $1.0 \mathrm{mM}$, and this concentration was chosen to test for its protective role against cisplatin toxicity. At 0.10 and $0.25 \mathrm{mM}$ cisplatin, CNs pretreated with D-Met showed significantly reduced excitation compared to $\mathrm{CNs}$ not pretreated with D-Met. The cisplatin-induced activity remained closer to the reference activity. Pretreatment with D-Met showed even more remarkable protection at $0.5 \mathrm{mM}$ cisplatin exposures. Without D-Met pretreatment, the CNs exhibited total loss of activity at $420 \mathrm{~min}$ with extensive cell death. In the presence of D-Met, however, the CNs remained active and showed no overt morphological damage of the neurons. D-Met pretreatment, however, did not prevent network shutdown or cell death in CNs when exposed to $0.75 \mathrm{mM}$ cisplatin.

Pretreatment time was also found to be a crucial factor in the protection of CNs against cisplatin-induced neurotoxicity. D-Met applied to cultures $1.0-2.0 \mathrm{~h}$ prior to cisplatin exposure was found to exhibit protective effects, as opposed to simultaneous application of D-Met and cisplatin, wherein no protective effects were observed. Further, the recovery of cultures to original reference activity following cisplatin exposure was also greater for cultures with a one hour D-Met pretreatment. These findings indicate that the time of application of D-Met prior to cisplatin treatment is critical for its protective function.

The optical isomer L-Met was substantially less protective (Fig. 7). With cisplatin at $0.1 \mathrm{mM}$, D-Met retained the network activity close to the reference level, whereas L-Met allowed for 20-30\% excitation. However, for cisplatin at $0.5 \mathrm{mM}$, the difference in protection was more compelling. D-Met maintained a 30\% excitation at $420 \mathrm{~min}$ and showed no activity loss after medium changes. In the presence of L-Met, however, cisplatin decreased activity by $60 \%$, which was irreversible even after medium changes.

Pre-administration of D-Met has been shown to not interfere with cisplatin's antitumor action in appropriate animal models (Jones and Basinger, 1989; Cloven et al., 2000). Further D-methionine does not interfere with the tumor kill of cisplatin in combination with radiation or radiation alone (Vuyyuri et al., 2008). These studies were appropriately designed and powered to determine if any statistically significant antitumor interference occurred and used tumor models for cancers commonly treated with cisplatin clinically including ovarian cancer (Cloven et al., 2000), carcinosarcoma (Jones and Basinger, 1989) and murine squamous cell carcinoma cells (Vuyyuri et al., 2008). Reser et al. (1999) reported that D-methionine partially inhibited cisplatin's antitumor action but used only 3 animals per cell, showed a small but statistically insignificant effect and did not have adequate statistical power. They also used a breast cancer tumor model, a cancer not typically treated with cisplatin. Ekborn et al. (2002) reported that D-methionine reduced the area under the curve (AUC) of cisplatin $30 \%$ by binding to the cisplatin 
and assumed that the binding would reduce the antitumor efficacy of the cisplatin. However Deegan et al. (1994) clearly demonstrated that the cisplatin-methionine complex retains most of its cytotoxic activity against tumors which is consistent with the results of the testing in appropriate tumor models (Jones and Basinger, 1989; Cloven et al., 2000; Vuyyuri et al., 2008). Consequently, D-methionine appears to be an appropriate candidate for a clinical therapy to reduce the side effects of cisplatin therapy.

D-Met, which can effectively be delivered orally (Campbell et al., 2007) can presumably help circumvent the deleterious effects of cisplatin treatment if taken at an optimal period of time. It is possible that the required pretreatment time for patients in vivo will be longer than what is observed in cell culture. The demonstration of D-Met protection against high concentrations of cisplatin opens the possibility of chronic, low concentration investigations and also provides a quantitative margin of error and proof of principle for potential clinical applications.

D-Met has been shown to prevent or ameliorate peripheral cisplatininduced hearing threshold shifts, outer hair cell loss, loss of hair cell function, loss of spiral ganglion cell neurons, and damage to the stria vascularis in animals (Campbell et al., 1996, 1999, 2007; Gabaizadeh et al., 1997; Wimmer et al., 2004). However, to our knowledge, this investigation is the first evidence of direct cisplatin damage to the cortical neurons, in vitro, and the amelioration of this damage by an over-thecounter supplement - D-Met. If D-Met can provide protection for the central nervous system, including the central auditory system, from cisplatin-induced damage, perhaps the "chemobrain" consequences and the central component of cisplatin-induced ototoxicity and tinnitus could also be ameliorated. In vitro studies and clinical trials of D-Met to confirm these in vitro studies will be needed to determine how well the cortical protection observed in this study translates into the clinical arena.

\section{Conflict of interest statement}

Kathleen Campbell, is the sole inventor on the patents for D-methionine as a protective agent. Her patents are owned by her employer SIU School of Medicine.

Kamakshi Gopal: None.

Guenter W. Gross: None.

Ernest J. Moore: None.

Bibesh Shrestha: None.

Calvin Wu: None.

\section{Acknowledgments}

The authors thank Nga Nguyen for unfailing assistance with cell culture. EJM is supported in part by internal start-up funds from UNT. The Charles and Josephine Bowen memorial endowment to the CNNS also supported this research.

\section{References}

Al-Khatib T, Cohen N, Carret AS, Daniel S. Cisplatinum ototoxicity in children, long-term follow up. Int J Pediatr Otorhinolaryngol 2010;74(8):913-9. [Aug]

Brock P, Knight K, Freyer D, Campbell K, Steyger PS, Blakley BS, et al. Platinum-induced ototoxicity in children: a consensus review on ototoxicity, otoprotection and monitoring. J Clin Oncol 2012. [Epub 2012 Apr 30].

Campbell KC, Rybak LP, Meech RP, Hughes L. D-methionine provides excellent protection from cisplatin ototoxicity in the rat. Hear Res 1996;102(1-2):90-8.

Campbell KC, Meech RP, Rybak LP, Hughes LF. D-methionine protects against cisplatin damage to the stria vascularis. Hear Res 1999;138(1-2):13-28.

Campbell KC, Meech RP, Rybak LP, Hughes LF. The effect of D-methionine on cochlear oxidative state with and without cisplatin administration: mechanisms of otoprotection. J Am Acad Audiol 2003;14(3):144-56.

Campbell KC, Meech RP, Klemens JJ. Prevention of noise- and drug-induced hearing loss with D-methionine. Hear Res 2007;226:92-103.

Church MW, Kaltenbach JA, Blakley BW, Burgio DL. The comparative effects of sodium thiosulfate, deithyldithiocarbamate, fosfomycin and WR-2712 on ameliorating cisplatin-induced ototoxicity. Hear Res 1995;86(1-2):195-203.
Cloven NG, Re A, McHale MT, Burger RA, DiSala PJ, Rose GS, et al. Evaluation of D-methionine as a cytoprotectant in cisplatin treatment of an animal model for ovarian cancer. Anticancer Res 2000;20:4205-10.

Deegan P, Pratt I, Ryan M. The nephrotoxicity, cytotoxicity and renal handling of a cisplatin-methionine complex in male Wistar rats. Toxicology 1994;89:1-14.

Dehne N, Lautermann J, Petrat F, Rauen U, de Groot H. Cisplatin ototoxicity: involvement of iron and enhanced formation of superoxide anion radicals. Toxicol Appl Pharmacol 2001;174(1):27-34.

Eastman A. Activation of programmed cell death by anticancer agents: cisplatin as a model system. Cancer Cells 1990;2:275-80.

Einarsson EJ, Petersen H, Wiebe T, Fransson PA, Magnusson M, Moëll C. Severe difficulties with word recognition in noise after platinum chemotherapy in childhood, and improvements with open-fitting hearing-aids. Int J Audiol 2011;50(10):642-51. [Oct, Epub 2011 Aug 3].

Ekborn A, Laurell G, Johnstrom P, Wallin I, Eksborg S, Ehrsson H. D-Methionine and cisplatin ototoxicity in the guinea pig: D-methionine influences cisplatin pharmacokinetics. Hear Res 2002;165:53-61.

Gabaizadeh R, Staecker H, Liu W, Kopke R, Malgrange B, Lefebvre PP, et al. Protection of both auditory hair cells and auditory neurons from cisplatin-induced damage. Acta Otolaryngol 1997; 117:232-8

Gandara DR, Nahhas WA, Adelson MD, Lichtman SM, Podczaski ES, Yanovich S, et al. Randomized placebo-controlled multicenter evaluation of diethyldithiocarbamate for chemoprotection against cisplatin-induced toxicities. J Clin Oncol 1995;13(2): 490-6. [Feb].

Gopal KV, Gross GW. Auditory cortical neurons in vitro: cell culture and multichannel extracellular recording. Acta Otolaryngol 1996a;116:690-6.

Gopal KV, Gross GW. Auditory cortical neurons in vitro: initial pharmacological studies. Acta Otolaryngol 1996b;116:690-704.

Gopal KV, Gross GW. Unique responses of auditory cortex networks in vitro to low concentrations of quinine. Hear Res 2004;192(1-2):10-22.

Gross GW. Simultaneous single unit recording in vitro with a photoetched laser deinsulated gold multi-microelectrode surface. IEEE Trans Biomed Eng 1979; BME-26:273-9.

Gross GW. Multielectrode arrays. Scholarpedia 2011;6(3):5749.

Gross GW, Pancrazio JPP. Neuronal network biosensors. In: Knopf GK, Bassi AS, editors. Smart Biosensor Technology. Taylor and Francis Publishers, CRC Press; 2007. p. 177-201.

Gross GW, Schwalm FU. A closed chamber for long-term electrophysiological and microscopic monitoring of monolayer neuronal networks. J Neurosci Methods 1994:52:73-85.

Gross GW, Wen W, Lin J. Transparent indium-tin oxide patterns for extracellular, multisite recording in neuronal cultures. J Neurosci Methods 1985;15:243-52.

Gross GW, Azzazy JME, Wu MC, Rhoades BK. The use of neuronal networks on multielectrode arrays as biosensors. Biosens Bioelectron 1995;10:553-67.

Gross GW, Rijal-Oli S, Jones V, Hollmuller D, Karg M. High throughput microelectrode array platforms for quantitative pharmacology and toxicology. Proceedings of MEA 2006, BIOPRO, Baden-Wuerttemberg; 2006. p. 132-5.

Hamstra DA, Eisbruch A, Naidu MUR, Ramana GV, Sunkara P, Campbell KCM, et al. Pharmacokinetic analysis and phase I study of MRX-1024 in patients treated with radiation therapy with or without cisplatinum for head and neck cancer. Clin Cancer Res 2010;16(9):2666-76. [May 1].

Hansen SW, Helweg-Larsen S, Trojaborg W. Long-term neurotoxicity in patients treated with cisplatin, vinblastine, and bleomycin for metastatic germ cell cancer. J Clin Oncol 1989;7(10):1457-61. [Oct].

Hoistad DL, Ondrey FG, Mutlu C, Schachern PA, Paparella MM, Adams GL. Histopathology of human temporal bone after cis-platinum, radiation, or both. Otolaryngol Head Neck Surg 1998;118(6):825-32.

Jamieson ER, Lippard SJ. Structure, recognition, and processing of cisplatin-DNA adducts. Chem Rev 1999;99:2467-98.

Jiang Y, Guo C, Vasko MR, Kelley MR. Implications of apurinic/apyrimidinic endonuclease in reactive oxygen signaling response after cisplatin treatment of dorsal root ganglion neurons. Cancer Res 2008;68(15):6425-34.

Johnstone AFM, Gross GW, Weiss DG, Schroeder O, Gramowski A, Shafer TJ. Micro-electrode arrays: a physiologically-based neurotoxicity testing platform for the 21st century. Neurotoxicology 2010;31:331-50.

Jones MM, Basinger MA. Control of nephrotoxicity in the rat during repeated cis-platinum treatments. J Appl Toxicol 1989;9(4):229-33.

Jones MM, Basinger MA, Holscher MA. Relative effectiveness of some compounds for the control of cisplatin-induced nephrotoxicity. Toxicology 1991;68(3):227-47.

Kaasa S, Olsnes BT, Mastekaasa A. Neuropsychological evaluation of patients with inoperable non-small cell lung cancer treated with combination chemotherapy or radiotherapy. Acta Oncol 1988;27(3):241-6.

Keefer EW, Gramowski A, Gross GW. NMDA receptor dependent periodic oscillations in cultured spinal cord networks. J Neurophysiol 2001a;86:3030-42.

Keefer EW, Gramowski A, Stenger DA, Pancrazio JJ, Gross GW. Characterization of acute neurotoxic effects of trimethylolpropane phosphate via neuronal network biosensors. Biosens Bioelectron 2001b;16(7-8):513-25.

Knight KR, Kraemer DF, Neuwelt EA. Ototoxicity in children receiving platinum chemotherapy: underestimating a commonly occurring toxicity that may influence academic and social development. J Clin Oncol 2005;23(34):8588-96. [Dec 1]

Knight KR, Kraemer DF, Winter C, Neuwelt EA. Early changes in auditory function as a result of platinum chemotherapy: use of extended high-frequency audiometry and evoked distortion product otoacoustic emissions. Clin Oncol 2007;25(10):1190-5. [Apr 1].

Kolinsky DC, Hayashi SS, Karzon R, Mao J, Hayashi RJ. Late onset hearing loss: a significant complication of cancer survivors treated with cisplatin containing chemotherapy regimens. J Pediatr Hematol Oncol 2010;32(2):119-23. [Mar]. 
Kovarík J, Svec F, Thurzo V. The effect of cis-dichlorodiammineplatinum (II) and acronycin on the proliferation and respiration of HeLa cells in vitro. Neoplasma 1972;19(6):569-77.

Lauenstein L, Meyer GJ, Sewing KF, Schober O, Hundeshagen H. Uptake kinetics of $14 \mathrm{C}$ L-leucine and $14 \mathrm{C} \mathrm{L}$ - and $14 \mathrm{C} \mathrm{D}$-methionine in rat brain and incorporation into protein. Neurosurg Rev 1987;10(2):147-50.

Lynch ED, Kil J. Compounds for the prevention and treatment of noise-induced hearing loss. Drug Discov Today 2005;10(19):1291-8. [Oct 1].

McWhinney SR, Goldberg RM, McLeod HL. Platinum neurotoxicity pharmacogenetics. Mol Cancer Ther 2009;8(1):10-6.

Meech RP, Campbell KCM, Hughes LP, Rybak LPA. Semiquantitative analysis of the effects of cisplatin on the rat stria vascularis. Hear Res 1998;124:44-59.

Morefield SI, Keefer EW, Chapman KD, Gross GW. Drug evaluations using neuronal networks cultured on microelectrode arrays. Biosens Bioelectron 2000;15(7-8): 383-96.

Muldoon LL, Pagel MA, Kroll RA, Brummett RE, Doolittle ND, Zuhowski EG. Delayed administration of sodium thiosulfate in animal models reduces platinum ototoxicity without reduction of antitumor activity. Clin Cancer Res 2000;6(1):309-15. [Jan].

Namikawa K, Asakura M, Minami T, Okazaki Y, Kadota E, Hashimoto S. Toxicity of cisplatin to the central nervous system of male rabbits. Biol Trace Elem Res 2000;74(3):223-35.

Novellino A, Scelfo B, Palosaari T, Price A, Sobanski T, Shafer TJ, et al. Development of micro-electrode array based tests for neurotoxicity: assessment of interlaboratory reproducibility with neuroactive chemicals. Front Neuroeng 2011;V4(4):1-14.

Olivi A, Gilbert M, Duncan KL, Corden B, Lenartz D, Brem H. Direct delivery of platinum-based antineoplastics to the central nervous system: a toxicity and ultrastructural study. Cancer Chemother Pharmacol 1993;31(6):449-54.

Orgel E, Jain S, Ji L, Pollick L, Si S, Finlay J, et al. Hearing loss among survivors of childhood brain tumors treated with an irradiation-sparing approach. Pediatr blood cancer 2012;58(6):953-8. http://dx.doi.org/10.1002/pbc.23275. [Epub 2011 Jul 27].

Otto WC, Brown RD, Gage-White L, Kupetz S, Anniko M, Penny JE, et al. Effects of cisplatin and thiosulfate upon auditory brainstem responses of guinea pigs. Hear Res 1988;35(1):79-85.

Parviz M, Gross GW. Quantification of zinc toxicity using neuronal networks on microelectrode arrays. Neurotoxicology 2006;28(3):520-31.
Poirrier AL, Pincemail J, Van Den Ackerveken P, Lefebvre PP, Malgrange B. Oxidative stress in the cochlea: an update. Curr Med Chem 2010;17(30):3591-604

Potter SM, DeMarse TB. A new approach to neural cell culture for long-term studies. J Neurosci Methods 2001;110:17-24.

Rajeswaran A, Trojan A, Burnand B, Giannelli M. Efficacy and side effects of cisplatin- and carboplatin-based doublet chemotherapeutic regimens versus non-platinum-based doublet chemotherapeutic regimens as first line treatment of metastatic non-small cell lung carcinoma: a systematic review of randomized controlled trials. Lung Cancer 2008;59:1-11.

Reser D, Rho M, Dewan D. L- and D-methionine provide equivalent long term protection against CDDP-induced ototoxicity in vivo, with partial in vitro and in vivo retention of antineoplastic activity. Neurotoxicology 1999;20:731-48.

Rijal-Oli S, Gross GW. Determination of dissociation constants using spontaneous neuronal network activity recorded with microelectrode arrays in vitro. J Neurosci Methods 2008;173:183-92.

Rybak LP. Neurochemistry of the peripheral and central auditory system after ototoxic drug exposure: implications for tinnitus. Int Tinnitus J 2005;11(1):23-30.

Rybak LP, Whitworth CA, Mukherjea D, Ramkumar V. Mechanisms of cisplatin-induced ototoxicity and prevention. Hear Res 2007;226(1-2):157-67.

Stathopoulos GP. Liposomal cisplatin: a new cisplatin formulation. Anticancer Drugs 2010;21(8):732-6.

Vuyyuri SB, Hamstra DA, Khanna D, Hamilton CA, Marwart SM, Campbell KCM, et al. Evaluation of a D-methionine as a novel oral radiation protector for prevention of mucositis. Clin Cancer Res 2008;14(7):2161-70.

Whitney KA, Lysaker PH, Steiner AR, Hook JN, Estes DD, Hanna NH. Is "chemobrain" a transient state? A prospective pilot study among persons with non-small cell lung cancer. J Support Oncol 2008;6(7):313-21. [Sep-Oct].

Wimmer C, Mees K, Stumpf P, Welsch U, Reichel O, Suckfull M. Round window application of D-methionine, sodium thiosulfate, brain-derived neurotrophic factor, and fibroblast growth factor-2 in cisplatin-induced ototoxicity. Otol Neurotol 2004;25(1):33-40.

Wu C, Gopal KV, Gross GW, Lukas TJ, Moore EJ. An in vitro model for testing drugs to treat tinnitus. Eur J Pharmacol 2011;667:188-94.

Xia Y, Gross GW. Histiotypic electrophysiological responses to cultured neuronal networks to ethanol. Alcohol 2003;30:167-74 